\title{
Timing and Sequencing of Events Marking the Transition to Adulthood in Two Informal Settlements in Nairobi, Kenya
}

Donatien Beguy, Caroline W. Kabiru, Eliya M. Zulu, and Alex C. Ezeh

\begin{abstract}
Young people living in poor urban informal settlements face unique challenges as they transition to adulthood. This exploratory paper uses retrospective information from the baseline survey of a 3-year prospective study to examine the timing and sequencing of four key markers (first sex, marriage, birth, and independent housing) of the transition to adulthood among 3,944 adolescents in two informal settlements in Nairobi city, Kenya. Event history analysis techniques are employed to examine the timing of the events. Results indicate that there is no significant gender difference with regard to first sexual debut among adolescents. For many boys and girls, the first sexual experience occurs outside of marriage or other union. For males, the sequencing of entry begins with entry into first sex, followed by independent housing. Conversely, for females, the sequencing begins with first sex and then parenthood. Apart from sexual debut, the patterns of entry into union and parenthood do not differ much from what was observed for Nairobi as a whole. The space constraints that typify the two slums may have influenced the pattern of leaving home observed. We discuss these and other findings in light of their implications for young people's health and well-being in resource-poor settings in urban areas.
\end{abstract}

KEYWORDS Transition to adulthood, Timing, Sequencing, First intercourse, First union, First birth, First independent housing, Event history analysis, Informal settlements, Nairobi, Kenya

\section{INTRODUCTION}

The years from late adolescence through the 20s are a complex and dynamic period marked by key life course events that are often viewed as formal markers of the transition from adolescence to adulthood. These markers include leaving school, entering the labor force, leaving one's natal home, getting married, and becoming a parent. ${ }^{1,2}$ Cultural, economic, educational, demographic, and other social changes greatly impact the sequencing and relevance of these salient markers of adult status. For example, a comparative study of perceptions of the transition to adulthood among Chinese and American college students reveals that the Chinese assign greater importance to role transitions, such as marriage, parenthood, and completion of education, in defining adulthood than do Americans. ${ }^{3}$ Similarly, aboriginal college

Beguy, Kabiru, and Ezeh are with the African Population and Health Research Center (APHRC), Shelter Afrique Centre, Nairobi, Kenya; Zulu is with the African Institute for Development Policy (AFIDEP), Nairobi, Kenya.

Correspondence: Donatien Beguy, African Population and Health Research Center (APHRC), Shelter Afrique Centre, Nairobi, Kenya. (E-mail: dbeguy@aphrc.org) 
students in Canada place more value on these life course transitions than their European Canadian compatriots. ${ }^{4}$ There is evidence that the "transition" period in Western societies has lengthened considerably, ${ }^{5,6}$ leading scholars such as Arnett ${ }^{6}$ to argue for a theory of development that captures a period distinct from adolescence and young adulthood that he calls "emerging adulthood" around 18-25 years. In his perspective, this period is characterized by independent exploration, and experimentation without the "dependency of childhood and adolescence" nor the "enduring responsibilities that are normative in adulthood" (p. 469).

Evidence drawn from Western societies may not be applicable in developing countries since socio-cultural and economic differences are likely to have significant impacts on the way young people experience the change from adolescence to adulthood. For example, studies conducted in African capital cities such as Dakar, Bamako, Lomé, Yaoundé, and Nairobi show that greater access to educational opportunities, changes in social values, lack of employment opportunities and increasing uncertainty about the future play a significant role in influencing the transition from childhood to adulthood. $^{7,8}$ These studies, however, mainly focus on the effect of macroeconomic changes on economic integration and demographic behavior of the city dwellers by using information collected from different generations of adults to examine the transition from adolescence to adulthood. Although these studies help better understand transitions to adulthood in sub-Saharan African cities as a whole, little is known about the entry into adult life in the rapidly growing urban slum settlements in African cities, which are characterized by extreme poverty and poor living conditions. In particular, there is limited research clarifying the linkages between the slum context and the timing, sequencing, and long-term consequences of major markers of the transition to adulthood.

The main objective of this paper is, therefore, to examine the timing and sequencing of critical events marking transition to adulthood, including first sexual intercourse, marriage, independent housing, and parenthood in two poor urban informal settlements-Korogocho and Viwandani in Nairobi, Kenya's capital city. We aim to add to the emerging body of literature on transitions to adulthood in subSaharan Africa by investigating the timing and sequencing of salient markers of the transition to adulthood to see whether there is a specific pattern of transition into adulthood in Nairobi slums. We also examine the association between the timing of each of the four events and some selected variables known to be important factors of transition to adulthood.

Investigating transition into adulthood in slum settlements is important for several reasons. First, urban informal settlements constitute an opportune context in which to examine the passage to adulthood because of the unique challenges that young people face in these communities. Young people in these settlements grow up in a hostile environment characterized by high levels of unemployment, crime, substance abuse, poor schooling facilities, and lack of recreational facilities. ${ }^{9-12}$ For instance, adolescents in the slums of Nairobi fare much worse in terms of risky sexual behavior than adolescents who live in non-slum parts of the city and rural areas. ${ }^{13-15}$ These differences also prevail when one compares slum residents and other groups outside Nairobi, including the rural poor. ${ }^{14}$ Early sexual intercourse among slum residents has many dire consequences, including unwanted pregnancies and births and their associated risks, as well as high maternal and child morbidity and mortality. ${ }^{16}$ Early sexual debut may also lengthen the period of exposure to the risk of pregnancy and childbearing, especially in contexts where women have limited access to contraception. In fact, much of the high fertility in sub-Saharan Africa may 
be attributed to young age at first birth. The timing of the first birth is usually an indicator of future fertility patterns and larger completed family size is one of the long-term demographic effects of adolescent fertility. ${ }^{17}$

Second, while transitions to marriage, parenthood, and sexual debut have been widely documented in developing countries, ${ }^{18-21}$ the transition to independent housing has received much less attention, particularly in sub-Saharan Africa. Research conducted in other parts of the world shows that the pathways to independent housing differ by social class. For example, a study by Jones ${ }^{22}$ in Britain showed that youth from working-class families (defined as families with a father whose occupational class was manual work) were more likely to move to independent housing at marriage, while their middle-class peers (where the father was employed in non-manual work) were more likely to pursue their studies. Further, the latter were more likely to return to their natal homes for extended periods. For young people living in urban slums in sub-Saharan Africa, high levels of unemployment, limited educational opportunities, overcrowded houses, and other socio-cultural factors may present unique challenges to the formation of independent housing or may drive young people out of their natal homes at younger ages than observed elsewhere. This paper aims to contribute to a better understanding of this important marker of transition to adulthood in an African setting.

\section{BACKGROUND}

\section{Markers of Transition to Adulthood}

Sexual debut among young people is considered one of the primary markers of the transition to adulthood, ${ }^{23}$ especially in societies that promote virginity till marriage. While adolescent sexual behavior in sub-Saharan Africa is often studied in the context of reproductive health risk, ${ }^{24-26}$ sexual maturity, experimentation, and building of sexual partnerships are part of the normal process of human development. It is important, nevertheless, to understand age at initiation of sex because, apart from the health risks associated with early sexual debut, early sexual experiences often shape sexual values and social relationships that persist into adulthood. ${ }^{27}$

Although the validity and reliability of data reported on sexual activity has been often questioned in sub-Saharan Africa, ${ }^{28-32}$ previous evidence shows that in general, females tend to engage in first intercourse at an older age. For example, in Nairobi, the median age at first intercourse for females is estimated at 19.2 years compared to 17.2 years among their male compatriots. ${ }^{33}$ In sub-Saharan Africa, this has been attributed, in part, to socio-cultural norms that proscribe sexual activity for females, often until marriage, while endorsing sexual prowess among young males. ${ }^{34-36}$ Another key feature of the transition to first sex is that there has been an increase in the age at first sex in many African societies. In Kenya for instance, there is a delay in first sex among young people as evidenced by the 2003 and 20082009 KDHS. ${ }^{33,37}$ However, in societies where age at first sex is low and many young people initiate sex outside marriage, ${ }^{23}$ age at first sex may actually be seen more as a marker of the transition from childhood to adolescence as opposed to the transition from adolescence to adulthood.

Risk and protective factors associated with adolescent sexual behaviors include individual and family characteristics (e.g., level of education, schooling status, substance use, delinquent behavior, family structure, living arrangements, family 
stability, physical abuse, socioeconomic status, etc.), and socio-cultural factors (e.g., peer influences, gender-based attitudes towards sexual behaviors). In South Nyanza, Kenya, Magadi et al. ${ }^{19}$ established that among 10-19-year-old adolescent girls, later sexual debut is associated with higher socioeconomic status and educational level. They also found that the mother's level of education and communication with parents or fellow girlfriends were associated with late sexual debut among young girls.

While entry into marriage is a key marker of the transition to adulthood in many contexts, the increasing occurrence of premarital sex, premarital childbearing, and proportions of men and women who do not get married until much later in their lives (if at all) mean that marriage is losing its significance as a marker of adulthood. However, because marriage is associated with other key transitions, such as independent living and financial independence, ${ }^{5}$ and because most people globally bear children within the marriage places, it is often considered a decisive event in the transition to adulthood. Further, even in places where marriage is not always considered a marker of adulthood, such as in the USA, marriage continues to be highly valued and most young people aspire to be married. ${ }^{38}$ In Kenya, a slight increase in median age at first marriage has been observed among women: from 19.2 in 1998 to 19.7 in 2003 and 20.0 years in 2008 among the $25-49$ age cohort. ${ }^{33,37}$ In a study conducted among adolescents 10-19 years old living in informal settlements in Kenya, $16 \%$ of females and $2 \%$ of males reported that they had ever been married. ${ }^{39}$ In South Nyanza, higher socioeconomic status and educational level were associated with older age at first marriage among 10-19-year-old adolescent girls. ${ }^{19}$ Studies conducted in several African capital cities show that factors influencing delay in marriage among young city dwellers include higher levels of education, altered social values, and unemployment, among others. ${ }^{40,41}$

Although the vast majority of births take place within marriage, the increasing proportion of children born outside marriage means that childbearing is becoming an important marker of adulthood, especially for women. ${ }^{5}$ Age at childbearing has increased significantly both in the developed and developing worlds. In Kenya, for instance, the median age at first birth had risen from 19.6 years among women aged 25-29 years in 1998 to 20.1 years in 2003. ${ }^{33}$ Among 10-19-year-olds living in Kibera slum in Kenya in $2007,16 \%$ of females and $1 \%$ of males reported that they had begun childbearing. Among females, childbearing is higher among those who are married $(63 \%)$ than the never married $(28 \%) .{ }^{39}$ Previously identified factors associated with early adolescent childbearing in developing countries include low education level, unstable family structure, absence of a father figure, low self-esteem, low socioeconomic status, early sexual debut, experience of physical abuse, etc. ${ }^{42,43}$ Among young women in the USA, Aronson ${ }^{5}$ noted that the delay in the timing of childbearing for some women is driven by a desire to get married first or find the right partner, establish their careers, and/or achieve financial independence.

Independent housing is an important marker of the transition to adulthood because it signifies the beginning of individual responsibility. In a study among college students in the USA, Arnett ${ }^{44}$ noted that moving out of the natal home was endorsed by a majority of respondents as an important criterion for adult status. However, it is important to bear in mind that increased career flexibility and limited job opportunities also means that the pathway to residential independence is not necessarily linear, but may be circular, with young people leaving home for certain periods of time and then returning to their natal home when they experience financial difficulty. In Dakar and Bamako in Western Africa, Marcoux and Tokindang $^{45}$ stress the central role of financial independence on the access to 
independent housing, which is strongly delayed for males who are inactive, studying, or unemployed. Also, even when employed, younger generations of male city dwellers delayed their leaving of the parental home because of the increasing costs of renting a house.

While examination of each marker of the transition to adulthood is informative, the foregoing review demonstrates that it would even be more useful to view transition to adulthood as a process marked by the temporal sequence of some of its markers. In the USA, Marini ${ }^{2}$ reported that about half of male and female high school students in Illinois experienced exit from school first, followed in order by first job, first marriage, and first child. In Nairobi city, Agwanda et al. ${ }^{7}$ found strong gender and cohort differences in the ordering of key transition markers. For females, the most common ordering was the one in which employment occurs first, followed by union formation and parenthood for the older generation while for the younger generation, parenthood precedes union formation. For both generations of males, the most common pattern is the one in which employment occurs first, followed by own housing, union formation, and parenthood.

We expect the patterns of entry into adulthood to be different from what was observed elsewhere as we are studying a specific population-young people growing up in abject poverty in urban slums, depicted as facing critical challenges given their poor living conditions. The uniquely poor and hostile environment in which they live is likely to shape their experiences of various events marking transition to adulthood.

\section{DATA AND METHODS}

\section{Study Description and Procedures}

This paper draws on data collected under the Transition to Adulthood (TTA) project conducted among adolescents living in two of Nairobi's informal settlements, Korogocho and Viwandani. Both are located about $5-10 \mathrm{~km}$ from the city center and $3 \mathrm{~km}$ from each other. Korogocho has a more settled population, with a median duration of stay of 16 years for the current population. ${ }^{46}$ On the other hand, Viwandani, which is close to Nairobi's industrial area, attracts a youthful and highly mobile population seeking job opportunities in the nearby industries. The median duration of stay in Viwandani is 7 years, ${ }^{46}$ and its population is mostly male. Residents of Viwandani also have higher levels of education than Korogocho residents. The proportion of economically active individuals (aged 15-64 years old) is higher in Viwandani than in Korogocho (72\% vs. $62 \%$ in 2008). Conversely, Korogocho has a larger proportion of 0-4-year-olds than Viwandani (37\% vs. 28\% in 2008). Unstable and low-paying jobs are the main income-generating activities for most residents in the two slums. ${ }^{47}$

The TTA was designed to follow young people aged 12-22 years for 3 years in order to identify protective and risk factors in their lives and to examine how these factors are related to various markers of the transition to adulthood. The study is nested in the longitudinal Nairobi Urban Health and Demographic Surveillance System (NUHDSS), which covers nearly 72,000 people in 28,000 households in the two informal settlements every year. In the NUHDSS, fieldworkers collect information from all households within the Demographic Surveillance Area every 4 months on a wide range of issues including: demographic events (births, deaths, migrations, etc.); health outcomes and practices (morbidity in the last 2 weeks, 
vaccination, health-seeking behavior, etc.), and socio-economic status (education, household possessions and amenities, livelihood sources, etc.).

The NUHDSS database provided the sampling frame that was used to randomly select young people aged 12-22 in the two slum settlements. During the first wave of the 3-year study (November 2007-June 2008), 4,058 randomly selected adolescents (50\% males) aged 12-22 were interviewed. This number reflects an overall $75 \%$ response rate of the targeted sample $(5,398)$. Korogocho had a higher response rate $(80 \%)$ than Viwandani $(71 \%)$, mostly due to the differences in the levels of mobility and economic activities between the two study sites.

The analytic sample includes 3,944 adolescents since we omitted 114 individuals $(3 \%)$ with inconsistent or missing data on age, date of birth, and/or age at first event.

The Kenya Medical Research Institute's ethical review board provided ethical approval for the study. Signed or verbal consent was obtained from all respondents. For respondents aged 12-17 years, parental consent was also obtained. The questionnaire was translated and administered in Swahili, Kenya's national language.

\section{Measures}

Outcome Variables. For each first event (independent housing, union (i.e., marriage or cohabitation), sexual intercourse, and childbearing), the outcome variable is based on answers to three questions. For instance, the outcome variable for first independent housing is based on answers to the following questions: "Have you ever owned or rented your own residence, such as a structure or house?" and if so, "In what month and year did you first own or rent your own residence" and "How old where you when you first owned or started renting your own residence?" The outcome variable is the age at which a person makes the transition to first independent residence (uncensored individuals) or age at interview if the event had not occurred as at the time of the survey (censored individuals). Similar questions are used to compute outcome measures for the transitions to first union, first sexual intercourse, and first parenthood. For every event, a dichotomous variable (coded 1 if the event occurred and 0 if not) is used to define the censoring status. For example, for union, the censoring variable is coded 1 (yes) if the individual is married/living together and 0 (no) if never married or cohabited. The terms marriage and union are used interchangeably as our definition of marriage is broad and encompasses formal as well as informal marriage (cohabitation).

In our study communities, defining independent housing is complex. The housing structure in these settlements may obligate a young person to live in a different structure from his or her parents due to space constraints or specific cultural reasons. This may not necessarily mean that the young person concerned actually owns the house, or is responsible for paying the rent. Since our aim was to find out whether the respondent had ever independently owned or rented his/her own place of residence, fieldworkers were trained to explain that living in a house separate from one's parents/guardians without actually being the owner or responsible for the rent payment does not count as independent housing.

For childbearing, the censoring variable is coded 1 (yes) when the individual gets a first child and 0 (no) otherwise. For boys, this corresponds to the date the woman they impregnate gives birth. Although the recall of past events may be difficult for all the individuals, it is worth noting that this can be exacerbated for boys who may not be able to know the precise date of delivery by the mother of their child. Boys may also underreport their fertility as they may not be aware of their impregnating a girl, or deliberately omit it. 
Explanatory Variables. Possible factors associated with transition to adulthood in the literature are considered in this analysis. Also, when possible, dummy variables related to key transition to adulthood markers serve as explanatory factors in the regression models of each event as they are likely to precede the event being analyzed. The latter variables were included as time-varying variables. For each event, the corresponding independent variable is coded 1 if the event occurs and 0 otherwise. For example, marriage is coded 1 if the individual is married or lives together with a partner, and 0 otherwise. Marriage is included as an independent variable in the analysis of timing to sexual debut, first child, and first independent housing. Similarly, independent housing is also used in the models regarding marriage, sexual debut, and parenthood. First sexual experience serves as an independent variable in the analysis of timing to first child, while the latter is used in the analysis of first independent housing and first union.

Socio-demographic characteristics used in all four regression models include study site (Korogocho vs. Viwandani), age cohort, educational level, ethnic group, religion, place of birth (born in slum vs. born outside), schooling status (in school vs. out of school; see Table 2). Three age groups are considered: $12-14,15-17$, and 1822 years. Educational attainment is divided into three categories: no education, primary education, secondary education or higher. Ethnicity comprises six groupsKikuyu, Luyha, Luo, Kamba, Somali-and a residual group of other ethnic groups. Religion has six categories: no religion, Catholic, Protestant, Pentecostal, Muslim, and a residual group of other religious groups. Socio-economic status is measured through a set of variables that characterize household asset ownership, using principal component analysis. ${ }^{48}$ Three categories were considered: least wealthy, middle, and most wealthy. Lastly, a variable indicating whether the respondent has ever used contraception was used in the analysis of the timing to first child (yes vs. no).

\section{Analytic Approach}

All analyses are conducted using Stata 10.1. Event history analysis techniques are employed to examine the timing of the events that mark the passage to adulthood in the two informal settlements. ${ }^{49,50}$ Each analysis of the considered event (first sexual intercourse, first independent housing, first union, and first child) consists of measuring the time between a starting point common to all individuals who can possibly experience the event and the date of the occurrence of the event, or the date of exit from observation (time of survey). To allow first events to be censored (individuals may not have experienced the event by the time of survey), age at first events are treated as time-to-event data. For example, in the study of first sexual intercourse, individuals are considered from their birth until they first have sex or the time of the survey for those who were not yet sexually experienced. For the latter, the eventual age at first sex is "censored". For individuals who have yet to reach a particular age and who have not experienced the event of interest, the risk of occurrence of the event of interest at that age is assumed to be the same as it is for individuals who have reached that age. For each transition, survival curves are derived from Kaplan-Meier estimates using the complement to 1 of the probability of not having made the particular transition at a specific age. We also examine the sequencing of key events as well as the time lag between consecutive events. Cox's proportional hazards model are used for the multivariate analysis, since they do not need specification of the form of the distribution of the baseline hazard rate. ${ }^{51-53}$ These models also allow for use of time-varying covariates, i.e., characteristics acquired in each phase of life explaining an event's occurrence and see whether they 
hasten or slow down the timing of occurrence of the first event studies. The Cox model asserts that the hazard rate is:

$$
h(t / z j)=h 0(t) \cdot \exp (\beta j z j(t)),
$$

where the regression coefficients are to be estimated from the data. $h 0(t)$ is the baseline hazard function (the hazard when $z=0) . \mathrm{Zj}(t)$ is the individual covariates vector and $\beta j$ is a vector of the regression parameters that indicate the effects of these covariates, some of them varying with $t$ (hence the term time-varying covariate). The relative hazard are given by $\exp (\mathrm{zj}(t) \beta)$.

\section{Study Limitations}

Study findings should be interpreted in light of several limitations. First, analysis is based on self-reported information that is subject to biases and recall lapses. For example, there is possible under-reporting of live births where the child died shortly after birth. Also, retrospective reporting of timing of first sex, first birth, marriage, and independent housing may affect their accuracy. It is also noteworthy that marriage may not be a discrete event, with its occurrence being likely to span over a period of months or even years. ${ }^{54}$ Its timing may be thus inadequately reported as it may be quite difficult to date the beginning of first union or to determine the single stage of the marriage process that captures the marriage date. Furthermore, as noted by other studies, ${ }^{28,32,55,56}$ reporting of sensitive behavior such as sexual activity is often inconsistent although the quality depends on the mode of data collection. ${ }^{29,30}$ Second, most of the independent variables are time-invariant (apart from the four events themselves), thus limiting the possibility of inferring precise causality. They are collected as of the moment of survey and not at the time they occurred. As a result, most of the findings do not infer causation apart from those related to the four events. They rather denote association between the independent variables and each of the key transition markers.

It is also important to note that the dating of each event may be affected by age heaping. ${ }^{57}$ For example, $21 \%$ of cases of first sexual intercourse were reported to have occurred at ages 10,15 , and 20 . This preference of round numbers is estimated at $18 \%$ for first union, $22 \%$ for first child and $25 \%$ for first independent housing. Also, $79 \%$ of adolescents reported the exact month of occurrence of sexual debut. This is the case of $96 \%$ for first union, $99 \%$ for first child, and $89 \%$ for first independent housing.

\section{RESULTS}

\section{Sample Description}

Table 1 displays descriptive characteristics for the 3,944 participants in the analytic sample. About $32 \%$ reported having had sexual intercourse, $10 \%$ had ever been married or lived together with a partner, $12 \%$ had had a child, and $17 \%$ reported having ever owned or rented a house. Respondents were, on average, 16.6 years old; $50 \%$ were male, $48 \%$ were living in Viwandani and $51 \%$ in Korogocho. Kikuyus comprised $34 \%$ of the sample; Luos, $17 \%$; Kambas, $17 \%$; Luhyas, $13 \%$; and Somalis, $11 \%$. Fifty-six percent were born in the slum area, $38 \%$ in rural areas, and $6 \%$ in urban Kenya or neighboring countries. Sixty-seven percent of the respondents had attained primary level of education while $32 \%$ had at least some secondary level 
education. Only $1 \%$ had never attended school. At the time of the survey, $58 \%$ of adolescents were attending school.

\section{Timing of Key Transitions}

Table 2 shows the probability that an adolescent will experience any of the four transition events by a particular age, for the whole sample and by gender.

Timing of First Sexual Intercourse. For sexual debut, $18 \%$ of adolescents had engaged in first sexual intercourse by age $16 ; 58 \%$ and $73 \%$ had done so by age 20 and 22, respectively. Median age at first sex is estimated at 19.1 years. Males are more likely to have sex than females before age 16 but the opposite holds after age 16. For example, $14 \%$ of males and $10 \%$ female had engaged in first sexual intercourse by age 15 , whereas $53 \%$ of males and $62 \%$ females had done so by age 20 . By age 22 , about $73 \%$ males and $74 \%$ females were sexually experienced. Median age at first sex is estimated at 19.5 and 18.9 years, respectively, for boys and girls. Tests of survival curves shows that overall, these gender differences in first sexual intercourse are not significant at the $5 \%$ level.

Timing of First Union. Overall, about $10 \%$ of adolescents enter into union by age 18, with females entering into first union earlier than males $(18 \%$ of adolescent girls as compared with $2 \%$ of their male counterparts at that age). By age $22,21 \%$ were already married or living with a partner (34\% of girls vs. $7 \%$ of boys). Median age is not obtained; however, the first quartile suggests that $25 \%$ of females get married by age 18.8 .

Timing of Entry Into Parenthood. About $9 \%$ of adolescents have their first child by age 18 ; this percentage increases to $22 \%$ by age 20 . As expected, female adolescents enter into parenthood earlier than their male counterparts. For example, by age 18 , $16 \%$ of girls have given birth compared to only $2 \%$ of similarly aged boys who reported having fathered a child. The gender difference in entry into parenthood increases by age; $60 \%$ of girls compared to $13 \%$ of boys have become parents by age 22. These trends are confirmed by median age at first birth which is only obtained for girls (20.7 years). Gender differences are statistically significant (1\% level).

Timing of First Independent Housing. About 3\% of adolescents were living independently by age 15; the percentage increases to $13 \%$ and $31 \%$ by age 18 and 20, respectively. Males acquire their first independent housing earlier than their female counterparts. About $7 \%$ of males and $3 \%$ of females acquired their first independent residence by age 16 . By age $22,61 \%$ of males and $35 \%$ of females were renting or living in their own houses. Median age at first independent housing was only attained for boys, with half of them being residentially independent at age 20.7.

\section{Sequencing of the Events}

The sequencing of key transitions was determined using measures of the timing of the different events studied. Two orderings are constructed: one with marriage, parenthood, and own housing (Table 3) and the other with sexual intercourse, marriage, and own housing as events (Table 4). The first sequencing was determined based on those who have experienced at least one of the three events considered (marriage, parenthood, and own housing). Seventy-eight percent of adolescents 


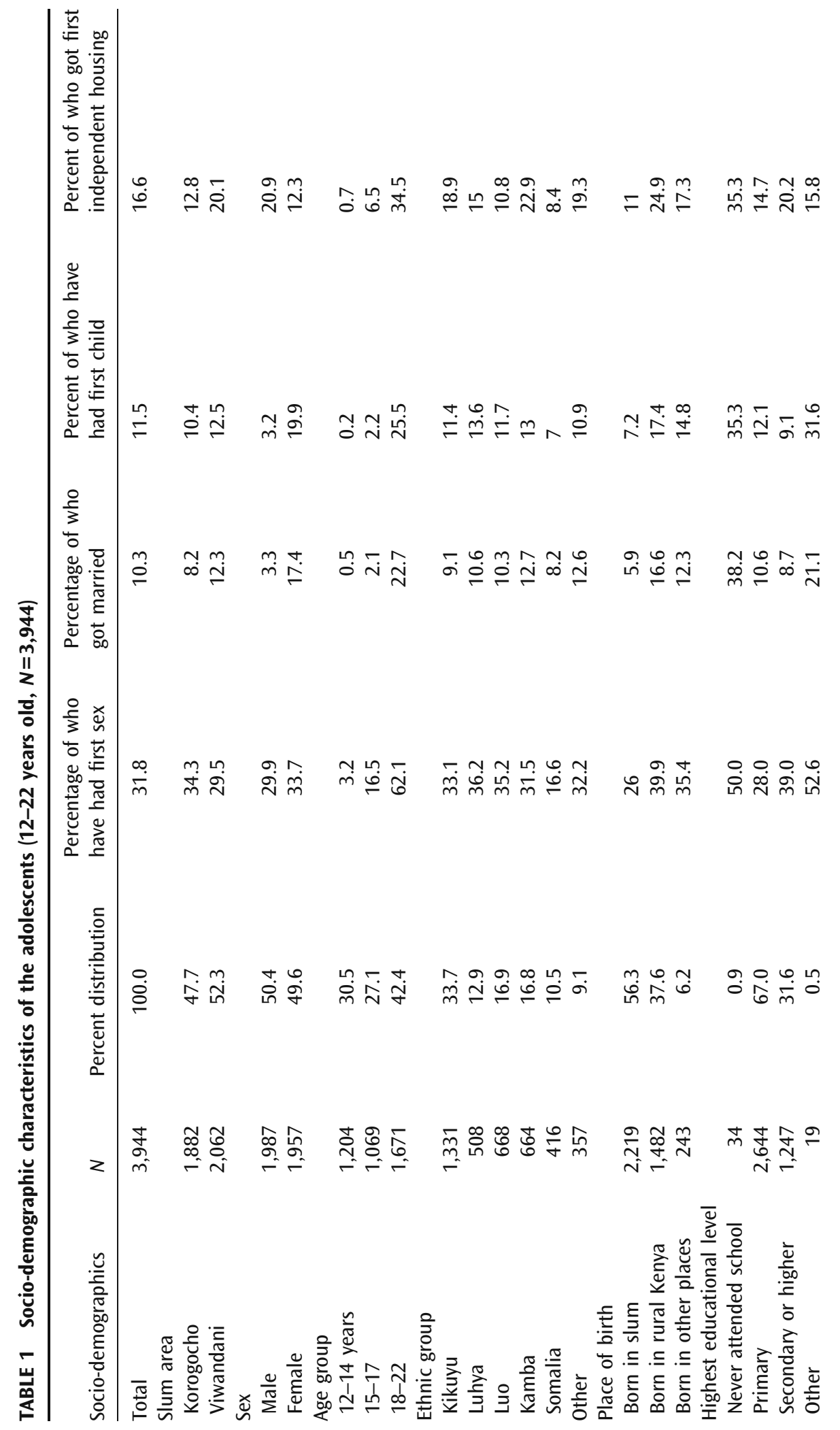




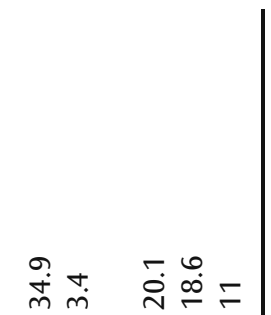

ํํำ ํํำ

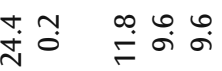

సேํำ

$\stackrel{\square}{\bar{\sigma}} \underset{\dot{\infty}}{\stackrel{m}{m}} \stackrel{m}{m} \bar{m} \bar{m}$

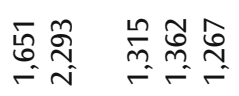

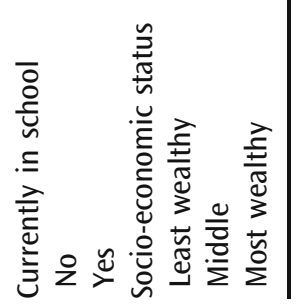




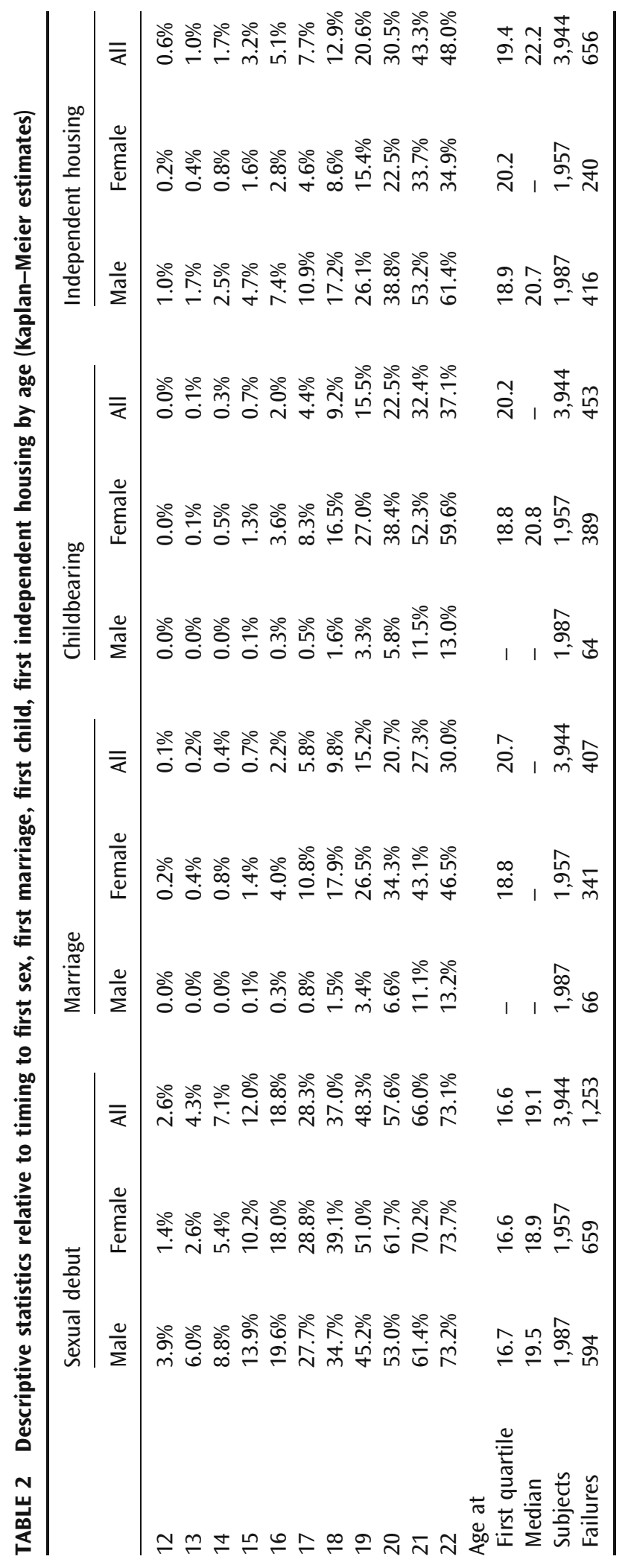


TABLE 3 Sequencing of marriage, childbearing, and independent housing

\begin{tabular}{llll}
\hline & Sex & & \\
\cline { 2 - 3 } Sequencing & Male & Female & Total \\
\hline Total \% of marriage first & 5.5 & 47.9 & 28.4 \\
M_H_C & 1.4 & 7.8 & 4.9 \\
M_H & 1.6 & 2.7 & 2.2 \\
M_C_H & 0.7 & 5.3 & 3.2 \\
M_C & 0.9 & 25.2 & 14.1 \\
M & 0.9 & 6.8 & 4.1 \\
Total \% of housing first & 90.6 & 24.0 & 54.5 \\
H_M_C & 4.6 & 6.6 & 5.7 \\
H_M & 3.5 & 2.2 & 2.8 \\
H_C_M & 0.5 & 0.4 & 0.4 \\
H_C & 2.8 & 2.5 & 2.6 \\
H & 79.3 & 12.3 & 43.0 \\
Total \% of child first & 3.9 & 28.1 & 17.0 \\
C_M_H & 0.2 & 2.2 & 1.3 \\
C_M & 0.5 & 7.0 & 4.0 \\
C_H_M & 0.5 & 0.4 & 0.4 \\
C_H & 0.9 & 4.5 & 2.9 \\
C & 1.8 & 14.1 & 8.5 \\
Total & 100.0 & 100.0 & 100.0 \\
N & 434 & 512 & 946 \\
\hline
\end{tabular}

$M$ marriage, $C$ child, $H$ housing, $M \_C \_H$ means marriage followed in order by child and own housing

TABLE 4 Sequencing of marriage, sexual intercourse, and independent housing

\begin{tabular}{llll}
\hline & Sex & & \\
\cline { 2 - 3 } Sequencing & Male & Female & Total \\
\hline Total \% of marriage first & 1.0 & 10.5 & 5.6 \\
M_H_S & 0.0 & 0.9 & 0.4 \\
M_S_H & 0.6 & 2.1 & 1.3 \\
M_S & 0.4 & 6.9 & 3.6 \\
M & 0.0 & 0.6 & 0.3 \\
Total \% of housing first & 29.8 & 12.5 & 21.3 \\
H_M_S & 0.4 & 1.8 & 1.1 \\
H_S_M & 2.1 & 2.6 & 2.3 \\
H_S & 8.9 & 1.8 & 5.4 \\
H & 18.4 & 6.2 & 12.4 \\
Total \% of sex first & 69.2 & 77.1 & 73.1 \\
S_M_H & 1.8 & 10.0 & 5.9 \\
S_M & 1.0 & 20.8 & 10.7 \\
S_H_M & 2.9 & 2.6 & 2.7 \\
S_H & 22.1 & 5.9 & 14.2 \\
S & 41.5 & 37.8 & 39.7 \\
Total & 100.0 & 100.0 & 100.0 \\
N & 728 & 707 & 1,435 \\
\hline
\end{tabular}

$M$ marriage, $S$ sexual intercourse, $H$ housing 
(78\% males vs. $74 \%$ females) had not experienced any of the three events and are excluded from the first sequencing analysis. Similarly, the second ordering was done on only those for whom first sexual intercourse, marriage or own housing had occurred. About $64 \%$ of adolescents (63\% males vs. $64 \%$ females) had not experienced any of these events and are thus excluded from the sequencing analyses.

Sequencing of Marriage, Parenthood, and Independent Housing. Overall, for about $90 \%$ of male adolescents, the first event experienced is residential independence. For the vast majority $(79 \%)$, residential independence was the only transition experienced by the time of survey. Five percent achieved residential independence first, followed in order by first marriage and first child. About $4 \%$ got independent housing and then got married, and 3\% got independent housing first followed by the first child.

The sequencing is more diverse among females. In total, $48 \%$ of female adolescents enter into union first, $28 \%$ first have a child, and 24\% initially move into their own home. For $7 \%$, first marriage was the only event experienced. For about a quarter, first union was followed by parenthood. Overall, $14 \%$ only experienced parenthood, $7 \%$ first had a child then got married, and $5 \%$ moved to their own housing following parenthood. Seven percent first moved into their own home and then got married and subsequently had a child.

Sequencing of Marriage, Sexual Intercourse, and Independent Housing. In total, for $69 \%$ of the boys, the initial transition was engaging in first sexual intercourse. For about $41 \%$ of boys, only first sex had been experienced while for $22 \%$, first sex was followed by establishing first independent housing. Three percent of the boys first transitioned into first sex, then established an independent residence, and subsequently entered into union. About $30 \%$ of the boys established independent residence first. Eighteen percent did not experience any other event later after acquiring the first independent housing, while $9 \%$ subsequently engaged in first sexual intercourse.

Among females, first sexual intercourse occurred first for $77 \%$. After the sexual debut, $41 \%$ did not experience any other event, $21 \%$ entered into union, $10 \%$ entered into union and then got their own housing, and $6 \%$ got their own housing. About $12 \%$ first got their own housing, and a similar percentage (10\%) first experienced marriage.

We complement the sequence analysis with analysis of time lag between events (Table 5). On average, first union and first birth are separated by 13.6 months when

TABLE 5 Time lag between events experienced

\begin{tabular}{llll}
\hline & \multicolumn{2}{l}{ Time lag } & Median \\
\cline { 2 - 4 } Sequence & $N$ & Mean & 11.0 \\
\hline Union-child & 263 & 13.6 & 11.4 \\
Child-union & 58 & 14.8 & 8.4 \\
Union-housing & 109 & 14.4 & 7.2 \\
Housing-union & 88 & 20.4 & 16.8 \\
Child-housing & 74 & 20.8 & 14.4 \\
Housing-child & 128 & 20.9 & 0.6 \\
Union-sex & 93 & 2.7 & 12.0 \\
Sex-union & 310 & 21.1 & 8.7 \\
Housing-sex & 133 & 18.0 & 32.1 \\
Sex-housing & 345 & 37.4 & \\
\hline
\end{tabular}


young people enter into union before having their first child, and 14.8 months when it is the reverse. The respective median time lags are 11.0 and 11.4 months. Young people get their first independent housing about 14.4 months (median duration is about 8.4 months) on average after getting married or living together. When they experience independent housing first, first union occurrs about 20.4 months later (median duration is about 7.2 months). The average duration between first child and first independent housing is about 20.8 months when the sequence is first child followed by first housing, and 20.9 if the sequence is the reverse. The respective median durations are 16.8 and 14.4 months.

Among those who experienced first sex after entering into union, the average duration between the two events is 2.7 months (median duration of 0.6 months). This time lag is about 21.1 months when first sex occurs before first union, with a median duration of 12 months.

On average, first sex and first independent housing are separated by 18.0 months (median duration of 8.7 months) when young people initiate sex after getting their first independent housing, and 37.4 (median duration of 32.1 months) when it is the reverse.

\section{Multivariate Analysis}

Table 6 displays hazard ratios from the Cox regression models. When the hazard ratio is greater than one, it means a higher risk of occurrence of first event in the corresponding category, as compared to the reference category. Conversely, the risk of experiencing a given event is lower when the hazard ratio is less than one. There is significant difference between the two slum communities in timing of sexual debut, access to independent housing, and entry into union when other factors are controlled for. Adolescents from Korogocho initiated sex, moved to independent housing, and entered into union later than their Viwandani counterparts. Age group was significantly associated with sexual debut, with younger adolescents experiencing first sex much later than their older counterparts; hazard ratios of sexual debut are reduced by $44 \%$ and $28 \%$ for $12-14$ and $15-17$ years old, respectively, as compared to those aged 18-22. It is worth noting that after controlling for slum residence, age group, gender, ethnicity, religion, and education level, we found that the two youngest groups entered union at a later age. However, the direction of the association only changed once school attendance was included in the model, with youngest adolescents entering into union significantly earlier than the oldest cohort. School attendance reduced the likelihood of entering into union at each age. This is consistent with literature showing that schooling delays entry into union. ${ }^{18,58}$

Socio-economic status was significantly associated with the timing of union and marginally associated with the timing of childbearing. Specifically, compared with the middle wealth group, youth from the wealthiest households made the transition to independent housing later. Although only marginally significant, youth from the wealthiest households were more likely to begin childbearing earlier than those from the middle wealth group.

Educational attainment was significantly associated with age at first occurrence of independent housing, union, and childbearing. For each of these transitions, youth having secondary or higher education were significantly more likely to experience the event later than youth with only primary education. In addition, school attendance significantly reduced the hazards of experiencing each of the four transition markers at every age.

Place of birth was associated with the timing of first independent housing and union. Adolescents who were born in slums made the transitions to first independent 
TABLE 6 Factors associated with sexual debut, independent housing, first union, first child (hazard ratios, Cox models)

\begin{tabular}{|c|c|c|c|c|}
\hline \multirow[b]{2}{*}{ Variables } & \multicolumn{4}{|c|}{ Hazard ratios (standard errors) } \\
\hline & Sexual debut & $\begin{array}{l}\text { Independent } \\
\text { housing }\end{array}$ & Union & Child \\
\hline \multicolumn{5}{|c|}{ Slum residence (ref. Viwandani) } \\
\hline Korogocho & $0.67(0.05)^{* * * *}$ & $0.71(0.08)^{* * *}$ & $0.75(0.11)^{* *}$ & $1.05(0.13)$ \\
\hline \multicolumn{5}{|l|}{ Age group (ref. 18-22) } \\
\hline $12-14$ & $0.56(0.11)^{* * *}$ & $0.68(0.28)$ & $8.99(4.93)^{* * *}$ & $2.74(1.81)$ \\
\hline $15-17$ & $0.72(0.07)^{* * * *}$ & $1.25(0.19)$ & $0.93(0.22)$ & $1.14(0.25)$ \\
\hline \multicolumn{5}{|l|}{ Gender (ref. female) } \\
\hline Male & $0.99(0.06)$ & $2.49(0.22)^{* * *}$ & $0.16(0.02)^{* * * *}$ & $0.24(0.03)^{* * *}$ \\
\hline \multicolumn{5}{|l|}{$\begin{array}{l}\text { Socioeconomic status } \\
\text { (ref. middle) }\end{array}$} \\
\hline Least wealthy & $0.91(0.06)$ & $0.98(0.09)$ & $1.22(0.15)$ & $0.96(0.11)$ \\
\hline Most wealthy & $1.00(0.07)$ & $0.69(0.08)^{* * *}$ & $1.17(0.16)$ & $1.24(0.15)^{*}$ \\
\hline \multicolumn{5}{|l|}{$\begin{array}{l}\text { Ethnic group } \\
\quad \text { (ref. Kikuyu) }\end{array}$} \\
\hline Luhya & $1.09(0.10)$ & $0.69(0.09)^{* * *}$ & $1.05(0.18)$ & $1.27(0.20)$ \\
\hline Luo & $1.14(0.10)$ & $0.55(0.08)^{* * *}$ & $1.35(0.22)^{*}$ & $0.98(0.15)$ \\
\hline Kamba & $0.81(0.07)^{* *}$ & $0.85(0.09)$ & $0.93(0.15)$ & $0.78(0.11)^{*}$ \\
\hline Somali & $0.40(0.10)^{* * * *}$ & $0.35(0.11)^{* * *}$ & $1.24(0.60)$ & $0.38(0.14)^{* * *}$ \\
\hline Other & $0.97(0.11)$ & $0.68(0.10)^{* * *}$ & $1.41(0.27)^{*}$ & $0.71(0.14)^{*}$ \\
\hline \multicolumn{5}{|l|}{ Religion (ref. Catholic) } \\
\hline No religion & $0.79(0.09)^{* *}$ & $0.96(0.13)$ & $1.10(0.22)$ & $0.87(0.16)$ \\
\hline Protestant & $0.75(0.09)^{* *}$ & $0.93(0.10)$ & $1.01(0.15)$ & $0.93(0.12)$ \\
\hline $\begin{array}{l}\text { Pentecostal/other } \\
\text { Christian }\end{array}$ & $0.75(0.09)^{* *}$ & $0.76(0.09)^{* *}$ & $1.30(0.19)^{*}$ & $0.83(0.11)$ \\
\hline Muslim & $0.82(0.19)$ & $1.51(0.42)$ & $1.05(0.50)$ & $1.56(0.53)$ \\
\hline Other & $0.67(0.11)^{* *}$ & $1.19(0.22)$ & $1.23(0.28)$ & $0.74(0.17)$ \\
\hline \multicolumn{5}{|l|}{$\begin{array}{l}\text { Educational level } \\
\text { (ref. primary) }\end{array}$} \\
\hline No education & $1.26(0.31)$ & $1.56(0.56)$ & $1.69(0.57)$ & $1.52(0.37)^{*}$ \\
\hline Secondary or higher & $1.16(0.28)$ & $0.82(0.07)^{* *}$ & $0.50(0.06)^{* * *}$ & $0.66(0.08)^{* * *}$ \\
\hline Other & $1.19(0.70)$ & $2.36(1.06)^{*}$ & $0.68(0.39)$ & $2.54(1.39)^{*}$ \\
\hline Currently in school & $0.39(0.03)^{* * * *}$ & $0.36(0.05)^{* * *}$ & $0.03(0.01)^{* * *}$ & $0.05(0.03)^{* * *}$ \\
\hline Slum born & $0.92(0.07)$ & $0.82(0.08)^{* *}$ & $0.76(0.10)^{* *}$ & $0.99(0.12)$ \\
\hline Ever used contraception & & & & $0.82(0.10)$ \\
\hline Married/Lives together & $6.33(0.79)^{* * *}$ & $2.41(0.38)^{* * *}$ & & $9.82(1.13)^{* * *}$ \\
\hline $\begin{array}{l}\text { Lives in an independent } \\
\text { housing }\end{array}$ & $1.27(0.13)^{* *}$ & & $1.77(0.26)^{* * *}$ & $1.41(0.15)^{* * *}$ \\
\hline Experience first sex & & $1.56(0.15)^{* * *}$ & & \\
\hline Has first child & & $0.56(0.10)^{* * *}$ & $1.17(0.21)$ & \\
\hline Wald Chi-square & $656.300^{* * *}$ & $407.158^{* * *}$ & $291.274^{* * *}$ & $1,029.982^{* * *}$ \\
\hline Subjects (events) & $3,944(1,253)$ & 3,944 (656) & $3,944(407)$ & 3,944 (453) \\
\hline Time at risk (person-years) & $62,631.040$ & $65,880.274$ & $66,556.446$ & $66,583.285$ \\
\hline
\end{tabular}

${ }^{*} p<0.1,{ }^{* *} p<0.05,{ }^{* * *} p<0.01$ 
housing and union later than those born outside the slum. In other words, migrants were more likely to transition into independent housing and union early. Ethnicity was also associated with the timing of all events. Kikuyus, for example, moved into independent housing much earlier than all other major ethnic groups with the exception of Kambas.

As stated earlier, we also examined the role of key transitions to adulthood markers in predicting the timing of key events that they are likely to precede. As expected, being in union was associated with increased hazards of initiating sex, getting independent housing, or beginning childbearing at every age. Young people who were living independently were more likely to experience first sexual intercourse, enter into union, and get their first child earlier than those who had not acquired independent housing. Youth who had already initiated sex moved into independent housing earlier than those who had not engaged in sexual intercourse. Finally, entry into parenthood was associated with decreased hazards of getting independent housing.

\section{DISCUSSION}

Young people living in poor urban informal settlements face unique challenges as they transition to adulthood. This exploratory paper uses retrospective information from the baseline survey of a 3-year prospective study, to examine the timing and sequencing of four key markers of the transition to adulthood among adolescents in two informal settlements in Nairobi. According to our knowledge, a combination of these issues has not been examined among poor urban youth, and the findings of this study add to the growing body of literature on the transition process among adolescents living in various contexts in sub-Saharan Africa.

In contrast to other studies conducted in Nairobi, ${ }^{33}$ our study found no significant gender difference with regard to the timing of sexual debut. In many parts of sub-Saharan Africa, girls' premarital sexual experience is stigmatized and socially prohibited whereas boys' sexual activity is often seen as an act of pride/honor. ${ }^{34-36}$ Consequently, it is often expected that girls will underreport sexual experiences or provide an older age at sexual debut while, boys will overreport sexual experiences or indicate that they engaged in sexual intercourse early. Findings also show that younger adolescents living in the two slum settlements tend to postpone their first sexual experience, although this trend may be affected by the misreporting of age at sexual debut. However, results indicate that a significant proportion of adolescents are sexually experienced in their early ages. Other studies ${ }^{13,58,59}$ argue that the typical living arrangement in the slum settlements-entire families living in singleroom houses-contributes to early transition to first sex because children are purportedly exposed to parental sexual activity at an early age. This residential reality also necessarily pushes a lot of young people to leave their parental homes prematurely, as soon as they can start generating their own money to pay rent, since they cannot live in the same room with their parents when they are grown. Given that the two study sites are characterized by high HIV/AIDS prevalence, ${ }^{60}$ there is need to ensure that young people have access to sexual and reproductive health services. Also, as noted in South Nyanza where early sexual debut also prevails among adolescents, ${ }^{19}$ adolescent health intervention programs in the slums may need to target adolescents in their early ages if they want to succeed in reducing poor sexual outcomes among them. 
Adolescents who are still attending school are likely to engage in sexual activity at a later age, suggesting a protective role for the school environment as noted elsewhere. ${ }^{61}$ One would argue that sexually experienced adolescents may be underrepresented as they may be no longer attending school. It is, however, not possible to know whether adolescents are exposed to sex education programs that may be provided in their schools. Further analysis should examine whether there are genderbased differences with regard to the influence of schooling on sexual debut among adolescents in slums as evidenced elsewhere. ${ }^{15}$

As expected, marriage significantly increases the likelihood of initiation of sex at an earlier age. However, for $69 \%$ of boys and $77 \%$ of girls, sexual debut occurs outside of marriage or other union. This is consistent with previous research showing that first sex typically occurs outside of marriage. ${ }^{62}$ As first marriage is increasingly delayed, young people are more likely to experience premarital sexual activity and subsequently, premarital birth given their low level of contraception use and insufficient knowledge of reproduction. ${ }^{23,63}$ In some cases, these premarital pregnancies are unplanned and the young parents (and often the young mother) have little or no financial and/or social support. Among adolescents living in similar conditions in the Kibera slums in Nairobi, evidence shows that for the vast majority of teenage mothers, the first birth was unwanted and the first pregnancy was unintended. ${ }^{39}$ Adolescents who lived in independent housing initiate sex and begin childbearing earlier than their peers who had not moved into their own housing. Greater opportunities for sexual activity among adolescents living away from parental supervision in a context of relatively low contraceptive use may be advanced as possible explanation for these findings. Such adolescents may not benefit from parental support, supervision, and behavioral control, thus may be more likely to engage in risky sexual behaviors. Previous evidence shows that living with both parents is associated with lower chances of sexual activity among youth in sub-Saharan Africa. ${ }^{61}$ In the slums of Nairobi, a father's presence was found to prevent young girls from engaging into sex and experiencing an unwanted pregnancy. ${ }^{64}$

As expected, findings show that young girls transition to parenthood earlier than boys. Median age at first birth was 20.7 years for young women and $16 \%$ of females were already parents by age 18 . This suggests that some females have their first births while they are still young and thus, face special risks during pregnancy and delivery due to their level of physical maturity. In the poor slum settings where access to obstetric services is hindered by the lack of basic health facilities and the high cost of care, ${ }^{65}$ young parenthood becomes a health threat not only for the young women but also their children. These risks are heightened in the context of the relatively high prevalence of HIV/AIDS in slum settlements. In Nigeria, Omololu (cited by the National Research Council and Institute of Medicine) ${ }^{23}$ reported that female Yoruba adults who had their first birth during their adolescent years are more likely to have higher fertility by the time of survey, more likely to be in polygamous unions, and more likely to rely on parents' assistance for their subsistence. Also, in most developing countries, early childbearing often triggers school dropout, reduces the opportunities of future employment, and leads to poor living conditions. ${ }^{23}$ For those who are able to continue school, academic performance is likely to worsen, given the very possible conflict between childcare responsibilities and school work. As such, it is expected that young mothers in slum settlements are at high risk of getting into worsened living conditions. In a context where educational and employment opportunities are already scarce, early childbearing is therefore more likely to contribute to difficulties in completing school 
and finding gainful employment; thus, preventing the young people from "successfully" making the transition to adulthood.

As previously evidenced in developing countries, ${ }^{19,23}$ higher education level and school enrollment were associated with delayed childbearing. One possible explanation is that young people who are still in school are less likely to engage in sexual activity at earlier ages because of high levels of adult monitoring or fewer opportunities to engage in sexual intercourse. Moreover, among girls, those who have experienced sexual intercourse may be underrepresented in the school subsample because childbearing may increase the likelihood of dropping out of school.

With respect to union, results confirm that young boys enter into union much later than girls. As expected, married adolescents were more likely to have begun childbearing. It is obvious that union increases the frequency of fertile sexual intercourse. However, existing literature also shows that premarital childbearing is increasingly prevalent in the slum communities in Kenya. ${ }^{11}$ We also observe that a significant number of young females enter into marriage at a relatively younger age. Unfortunately, for some girls, early marriage means early childbearing which entails potential health risks for the young mother and the child. Early marriage may also limit educational opportunities and may occur when the young person is not fully prepared to take over marital and parental responsibilities. Conversely, education strongly deters entry into union for adolescents in the two slums, which is consistent with previous evidence in sub-Saharan Africa. ${ }^{58,66}$

As expected, our findings show that boys get their first independent residence much earlier than girls. This is consistent with the fact that, in many societies in sub-Saharan Africa, women are rarely residentially independent since they usually move directly from their natal home to their marital home. It is also worth noting that some married women may not consider themselves to be living independently, perhaps because of cultural interpretations of the husband being the household head and owner of the home. Further, in some ethnic groups in Kenya, boys are expected to leave their parental home at young ages to live independently once they undergo initiation rites. For example, Kikuyu boys are expected to move out of their parental home after undergoing circumcision, a rite of initiation which typically occurs around 13 years of age. In the slums, where the entire family shares a single room, a young Kikuyu male may therefore be forced to move to a separate dwelling place at a much younger age than his nonKikuyu peers. Our findings do suggest that Kikuyus move into independent housing much earlier than other ethnic groups living in the two slum communities.

It is worth noting that the timing of residential independence among young people living in the slum settlements may be influenced by space constraints in informal settlements. That is, youth may be prompted to establish a separate residence from that of their parents simply because space in their household of origin may not be sufficient. They thus leave their parent or guardian home to most likely rent a room/structure. Most people in slum settlements are tenants (seven out of eight). Also, given the high levels of poverty in the slums, leaving home may be unique and singular as it may not always coincide with full economically independent life. Many young people who leave home may still depend on their parents or guardians with regard to food or education. In addition, in the slum context, leaving home at young ages should not be always seen as a positive transition as it may lead young people to risky and delinquent behaviors such as early sexual intercourse, multiple sexual partnerships, substance, and alcohol use. ${ }^{13}$

In general, adolescents in Korogocho initiate sex, get independent housing, and enter into union later than their counterparts from Viwandani. Given that 
Viwandani has a more mobile population than Korogocho, these differences may reflect a greater number of young migrants in the former who move to the slum settlement in search for livelihood opportunities. Further, we observed that migrants transitioned into union and established an independent household earlier than nonmigrants. We postulate that young migrants may be prompted to rent or own a place to live as they may not have access to social or immediate family networks to house them upon arrival in the slums.

Marriage and sexual debut were observed to hasten the transition to first independent housing. In many societies in sub-Saharan Africa, it is expected that married people move out of their natal home to form their own household unit. It is surprising to note that adolescents who have entered parenthood experienced a delayed transition to independent housing. One would expect the opposite as forming a family is often associated with creating a new residential unit.

While this study examines the timing and sequences of markers of the transition to adulthood, it is critical to acknowledge that the process of becoming an adult is complex and young people place different meanings on what it means to be an adult. ${ }^{5}$ Disentangling these meanings would require systematic investigations on subjective meanings of adulthood that shed light on less salient psychological and individual markers that define adulthood, such as bearing responsibility for one's actions and independent decision making. ${ }^{44}$ In addition, this study focuses on young people living in informal settlements who are not representative of all young people living in Nairobi. A more nuanced investigation of the role poverty plays in the transition from adolescence to young adulthood would require extension of the study population to include wider representation of young people. Our data do not allow investigations of educational transitions and entry to the labor market. Changes in education have significantly impacted the transition to adulthood. ${ }^{66,67}$ In general, there are greater educational opportunities available, and as a result, entry into employment, marriage, and parenthood is increasingly being delayed. Data from future waves will allow us to examine these additional events.

\section{ACKNOWLEDGMENTS}

The Transitions-To-Adulthood study is part of a larger project on Urbanization, Poverty and Health Dynamics, that is funded by the Wellcome Trust (Grant Number GR $07830 \mathrm{M}$ ). This project is nested in the Nairobi Urban Health and Demographic Surveillance System (NUHDSS) which is part of the INDEPTH Network. Analysis and writing time is supported by funding from the Wellcome Trust (Grant Number GR 07830 M), the William and Flora Hewlett Foundation (Grant Number 20068376) and the Rockefeller Foundation (Grant Number 2008 AR 001). We are grateful to Philippe Bocquier, Richard Jessor, John Cleland, and colleagues at APHRC for their contributions, and to the youth in Korogocho and Viwandani for their participation in the study.

\section{REFERENCES}

1. Shanahan MJ. Pathways to adulthood in changing societies: variability and mechanisms in life course perspective. Annu Rev Sociology. 2000; 26: 667-692.

2. Marini MM. The order of events in the transition to adulthood. Sociol Educ. 1984; 57(2): 63-84. 
3. Badgers S, Nelson LJ, Barry CM. Perceptions of the transition to adulthood among Chinese and American emerging adults. Int J Behav Dev. 2006; 30(1): 84-93.

4. Cheah CSL, Nelson LJ. The role of acculturation in the emerging adulthood of aboriginal college students. Int J Behav Dev. 2004; 28(6): 495-507.

5. Aronson P. The markers and meanings of growing up: contemporary young women's transitions from adolescence to adulthood. Gend Soc. 2008; 22: 56-82.

6. Arnett JJ. Emerging adulthood: a theory of development from the late teens through the twenties. Am Psychol. 2000; 55(5): 469-480.

7. Bocquier P, Agwanda AO, Khasakhala A, Nyandega I, Owuor S, eds. Biography of three generations of Nairobi residents - thirty years of social urban history. Dakar: Codesria; 2009.

8. Antoine P, Ouédraogo D, Piché V. Trois Générations de Citadins au Sahel. Trente ans D’histoire Sociale à Dakar et à Bamako. Paris: Villes et Entreprises; 1998.

9. Taffa N. A comparison of pregnancy and child health outcomes between teenage and adult mothers in the slums of Nairobi, Kenya. Int J Adolesc Med Health. 2003; 15(4): 321-329.

10. Mugisha F, Zulu EM. The influence of alcohol, drugs and substance abuse on sexual relationships and perception of risk to HIV infection among adolescents in the informal settlements of Nairobi. J Youth Stud. 2004; 7(3): 279-293.

11. African Population and Health Research Center. Population and health dynamics in Nairobi's informal settlements: report of the Nairobi cross-sectional slums survey (NCSS) 2000. Nairobi: African Population and Health Research Center; 2002.

12. Mugisha F, Arinaitwe-Mugisha J, Hagembe BON. Alcohol, substance and drug use among urban slum adolescents in Nairobi, Kenya. Cities. 2003; 20(4): 231-240.

13. Zulu EM, Dodoo FN-A, Ezeh AC. Sexual risk-taking in the slums of Nairobi, Kenya, 1993-98. Popul Stud. 2002; 56(3): 311-323.

14. Zulu EM, Dodoo FN-A, Ezeh AC. Urban-rural differences in the socioeconomic deprivation—sexual behavior link in Kenya. Soc Sci Med. 2007; 64(5): 1019-1031.

15. Kabiru CW, Beguy D, Undie C-C, Zulu EM, Ezeh AC. Transition into first sex among adolescents in slum and non-slum communities in Nairobi, Kenya. J Youth Stud. 2010; 13 (4): 453-471.

16. Mensch BS, Singh S, Casterline JB. Trends in the timing of first marriage among men and women in the developing world. In: Lloyd CB, Behrman JR, Stromquist NP, Cohen B, eds. The changing transitions to adulthood in developing countries. Washington, DC: National Academies Press; 2005: 118-171.

17. Wulf D, Singh S. Sexual activity, union and childbearing among adolescent women in the Americas. Int Fam Plann Perspect. 1991; 17(4): 137-144.

18. Tambashe BO, Shapiro D. Family background and early life course transitions in Kinshasa. J Marriage Fam. 1996; 58(4): 1029-1037.

19. Magadi MA, Agwanda AO. Determinants of transitions to first sexual intercourse, marriage and pregnancy among female adolescents: evidence from South Nyanza, Kenya. J Biosoc Sci. 2009; 41: 409-427.

20. Singh S, Darroch JE. Adolescent pregnancy and childbearing: levels and trends in developed countries. Fam Plann Perspect. 2000; 32(1): 14-23.

21. Singh S, Samara R. Early marriage among women in developing countries. Int Fam Plann Perspect. 1996; 22(4): 148-157. \& 175.

22. Jones G. Leaving the parental home: an analysis of early housing careers. J Soc Policy. 1987; 16(1): 49-74.

23. National Research Council, Institute of Medicine. Growing Up Global. The changing transitions to adulthood in developing countries. Panel on transitions to adulthood in developing countries. Washington, DC: The National Academies Press; 2005.

24. Babalola S, Tambashe BO, Vondrasek C. Parental factors and sexual risk-taking among young people in Cote d'Ivoire. Afr J Reprod Health. 2005; 9(1): 49-65.

25. Bankole A, Biddlecom A, Guiella G, Singh S, Zulu E. Sexual behavior, knowledge and information sources of very young adolescents in four sub-Saharan African countries. Afr J Reprod Health. 2007; 11(3): 28-43. 
26. Eaton L, Flisher AJ, Aaro LE. Unsafe sexual behaviour in South African youth. Soc Sci Med. 2003; 56(1): 149-165.

27. Kelly GF. Sexuality today: the human perspective. 7th ed. New York: McGraw-Hill; 2001.

28. Zaba B, Pisani E, Slaymaker E, Boerma JT. Age at first sex: understanding recent trends in African demographic surveys. Sex Transm Infect. 2004; 80(Suppl II): ii28-ii35.

29. Mensch BS, Hewett PC, Erulkar AS. The reporting of sensitive behavior by adolescents: a methodological experiment in Kenya. Demography. 2003; 40(2): 247-268.

30. Hewett PC, Mensch BS, Erulkar AS. Consistency in the reporting of sexual behaviour by adolescent girls in Kenya: a comparison of interviewing methods. Sex Transm Infect. 2004; 80 (Suppl 2): ii43-48.

31. Gregson S, Todd J, Zaba B. Sexual behavior change in countries with generalised HIV epidemics? Evidence from population-based cohort studies in Sub-Saharan Africa. Sex Transm Infect. 2009; 85 (Suppl 1): i1-i2. doi:10.1136/sti.2009.036053.

32. Beguy D, Kabiru C, Nderu E, Ngware M. Inconsistencies in self-reporting of sexual activity among the young people in Nairobi, Kenya. J Adolesc Health. 2009; 45(6): 595-601.

33. Central Bureau of Statistics (CBS) [Kenya], Ministry of Health (MOH) [Kenya], ORC Marco. Kenya Demographic and Health Survey 2003. Calverton: CBS, MOH, and ORC Marco; 2004.

34. Campbell C, MacPhail C. Peer education, gender and the development of critical consciousness: participatory HIV Prevention by South African youth. Soc Sci Med. 2002; 55: 331-345.

35. Varga CA. How gender roles influence sexual and reproductive health among South African adolescents. Stud Fam Plann. 2003; 34(3): 160-172.

36. Munthali AC, Zulu EM. The timing and role of initiation rites in preparing young people for adolescence and responsible sexual and reproductive behaviour in Malawi. Afr J Reprod Health. 2007; 11(3): 150-167.

37. Kenya National Bureau of Statistics (KNBS), ICF Macro. Kenya demographic and health survey 2008-09. Calverton: KNBS and ICF Macro; 2010.

38. Carroll JS, Willoughby B, Badger S, Nelson LJ, Barry CM, Madsen SD. So close, yet so far away: the impact of varying marital horizons on emerging adulthood. J Adolesc Res. 2007; 22(3): 219-247.

39. Erulkar AS, Matheka JK. Adolescence in the Kibera slums of Nairobi, Kenya. Nairobi and New York: The Population Council; 2007.

40. Antoine P, Piché V, Ouédraogo D, eds. Trois Générations de Citatdins au Sabel. Trente Ans d'histoire sociale à Dakar et à Bamako. Paris: L'Harmattan (Villes et Entreprises); 1998.

41. Bocquier P, Khasakhala A. Factors influencing union formation in Nairobi, Kenya. $J$ Biosoc Sci. 2009; 41(04): 433-455.

42. Lion KC, Prata N, Stewart C. Adolescent childbearing in Nicaragua: a quantitative assessment of associated factors. Int Perspect Sex Reprod Health. 2009; 35(2): 91-96.

43. Baumgartner JN, Geary CW, Tucker H, Wedderburn M. The influence of early sexual debut and sexual violence on adolescent pregnancy: a matched case-control study in Jamaica. Int Perspect Sex Reprod Health. 2009; 35(1): 21-28.

44. Arnett JJ. Young people's conceptions of the transition to adulthood. Youth Soc. 1997; 29 (1): 3-23.

45. Marcoux R, Tokindang J. Une Émancipation Résidentielle Remise en Cause. In: Antoine P, Ouédraogo D, Piché V, eds. Trois Générations de Citadins au Sahel. Trente ans D’histoire Sociale à Dakar et à Bamako. 1st ed. Paris: Villes et Entreprises; 1998: 183205.

46. Muindi K, Zulu E, Beguy D, Mudege N, Batten L. Characteristics of recent in-migrants in the Nairobi Urban Health Demographic Surveillance System. XXVI IUSSP Conference. Marrakech, Morocco; 2009. 
47. Zulu E, Konseiga A, Muindi K, Darteh E, Mberu B. Migration and the urbanization of poverty in sub-Saharan Africa: the case of Nairobi City, Kenya. 2006 PAA Annual Meeting. Los Angeles; 2006.

48. Filmer D, Pritchett LH. Estimating wealth effects without expenditure data-or tears: an application to educational enrollments in states of India. Demography. 2001; 38(1): 115-132.

49. Cleves MA, Gould WW, Gutierrez RG, Marchenko YU. An introduction to survival analysis using Stata. 2nd ed. College Station, Texas: Stata Press; 2008.

50. Allison PD. Event history analysis: regression for longitudinal event data (quantitative applications in the social sciences). Beverly Hills: Sage; 1991.

51. Blossfeld H-P, Hamerle A, Mayer KU. Event history analysis. Statistical theory and application in the social sciences. Millsdale: Lawrence Erlbaum Associates; 1989.

52. Cox DR. Regression models and life-tables. J Roy Stat Soc B Stat Meth. 1972; 34(2): 187-220.

53. Cox DR, Oakes R. Analysis of survival data. New York: Chapman and Hall; 1984.

54. Antoine P, Adjamagbo A, Amétépé F, et al. Union and separation: love stories are never simple. In: Lelièvre E, Antoine P, eds. Fuzzy states and complex trajectories: observation, modelization and interpretation of life histories. Vol 6 (Méthodes et Savoirs). Paris: INED/ CEPED; 2009.

55. Lauritsen JL, Swicegood CG. The consistency of self-reported initiation of sexual activity. Fam Plann Perspect. 1997; 29: 215-221.

56. Palen L-A, Smith EA, Caldwell LL, Flisher AJ, Wegner L, Vergnani T. Inconsistent reports of sexual intercourse among South African high school students. J Adolesc Health. 2008; 42: 221-227.

57. Becker S, Diop-Sidibé N. Does use of the calendar in surveys reduce heaping? Stud Fam Plann. 2003; 34(2): 127-132.

58. Dodoo FN-A, Sloan MM, Zulu EM. Space, context and hardship: socializing children into sexual activity in Kenya slums. In: Agyei-Mensah S, Casterline JB, eds. Fertility and reproductive health in sub-Saharan Africa: a collection of microdemographic studies. Westport: Greenwood Press; 2003.

59. Amuyunzu-Nyamongo MK, Magadi MA. Sexual privacy and early sexual debut in Nairobi informal settlements. Commu Work Fam. 2006; 9(2): 143-158.

60. African Population and Health Research Center (APHRC). The economic, health, and social context of HIV infection in informal urban settlements of Nairobi (DRAFT). Nairobi: African Population and Health Research Center; 2008.

61. Blum RW. Youth in sub-Saharan Africa. J Adolesc Health. 2007; 41: 230-238.

62. Meekers D. Sexual initiation and premarital childbearing in sub-Saharan Africa. Popul Stud (Camb). 1994; 48(1): 47-64.

63. Mensch BS, Clark WH, Lloyd CB, Erulkar AS. Premarital sex, schoolgirl pregnancy, and school quality in Rural Kenya. Stud Fam Plann. 2001; 32(4): 285-301.

64. Ngom P, Magadi MA, Owuor T. Parental presence and adolescent reproductive health among the Nairobi urban poor. J Adolesc Health. 2003; 33(5): 369-377.

65. Izugbara CO, Kabiru CW, Zulu EM. Urban poor Kenyan women and hospital-based delivery. Public Health Rep. 2009; 124: 585-589.

66. Bledsoe C. Transformations in sub-Saharan African marriage and fertility. Ann Am Acad Pol Soc Sci. 1990; 510(1): 115-125.

67. Shapiro D, Tambashe BO. Education, employment, and fertility in Kinshasa and prospects for changes in reproductive behavior. Popul Res Policy Rev. 1997; 16: 259-287. 